\title{
Risperidone Related Raynaud's Phenomenon: An Adolescent Case
}

\author{
Serkan Güneş ${ }^{1}$, Özalp Ekinci ${ }^{2}$, Halenur Teke ${ }^{2}$, Veli Yıldırım² \\ ${ }^{1}$ Department of Child and Adolescent Psychiatry, Hatay State Hospital, Hatay, ${ }^{2}$ Department of Child and Adolescent Psychiatry, Mersin University \\ School of Medicine, Mersin, Turkey
}

\begin{abstract}
Raynaud's phenomenon is a recurrent vasospastic condition with reducing in peripheral blood flow due to cold, or emotional stress. White, blue and red discolorations occur during the attacks. Serotonin reuptake inhibitors, psychostimulants, and aripiprazole are reported to be related with Raynaud's phenomenon. Risperidone is an atypical antipsychotic drug with dopaminergic and serotonergic effects. In children and adolescents, risperidone is used for bipolar disorder, tic disorders, conduct disorder, schizophrenia, symptoms of irritability and self-mutilation. Here we report a case of Raynaud's phenomenon associated with risperidone in a 12-year-old boy. Raynaud's phenomenon occurred two weeks after starting risperidone and disappeared after stopping risperidone.
\end{abstract}

KEY WORDS: Raynaud's phenomenon; Risperidone; Adolescent; Child; Case report.

\section{INTRODUCTION}

Risperidone is an atypical antipsychotic drug that combines dopamine $\mathrm{D}_{2}$ and serotonin $5 \mathrm{HT}_{2}$ receptor antagonism. ${ }^{1)}$ It is a widely prescribed agent effective in bipolar disorder, tic disorders, schizophrenia, conduct disorder, irritability, self-mutilation, and behavioral problems due to autism spectrum disorder or mental retardation. ${ }^{2)}$ In children and adolescents, many studies have shown the effectiveness of risperidone in treating disruptive and aggressive behaviors. ${ }^{3)}$ Sedation, weight gain, hyperprolactinemia, parkinsonism, akathisia, dyskinesia, and dystonia are side effects that occur during risperidone use. ${ }^{1)}$ Vascular side effects such as orthostatic hypotension can also be seen with risperidone. ${ }^{4}$

Raynaud's phenomenon (RP) is a common vascular disease, characterized by white, blue, or red discoloration of effected body part due to cold, or emotional stress. The extremities are usually affected bilaterally when exposed to triggers. Whereas the pathophysiological mechanisms

Received: April 18, 2016/Revised: May 14, 2016

Accepted: June 15, 2016

Address for correspondence: Serkan Güneş, MD

Department of Child and Adolescent Psychiatry, Hatay State Hospital, Hatay, Turkey

Tel: +90-5542587368, Fax: +90-3262272440

E-mail: dr_sgunes@hotmail.com of RP are unclear, investigators have indicated that the phenomenon is caused by vasoconstriction, increased blood viscosity, and disturbance in microcirculation. Several drugs including beta blockers, ergot alkaloids, selective serotonin reuptake inhibitors, psychostimulants, atomoxetine, and aripiprazole have been reported to induce RP. ${ }^{6-11)}$

Hereby, we report the emergence of RP with risperidone use in a 12-year-old boy. Informed consent was taken from the patient's parents for publication of this case report.

\section{CASE}

A 12-year-old boy was evaluated in child and adolescent psychiatry clinic for irritability and aggression. He had been a hyperactive and irritable boy since early childhood. He exhibited aggressive behaviors such as property damage, setting fire, and fighting with friends. No problem with attention in classroom was evident, however he was reported not to study enough, therefore his academic performance was not good. His mental examination revealed normal perception, orientation, and memory functions. His affect was dysphoric, anxious, and irritable. There was no substance and another drug use, physical illness, drug allergy, trauma, or family his-

(ㄷ) This is an Open-Access article distributed under the terms of the Creative Commons Attribution Non-Commercial License (http://creativecommons.org/licenses/by-nc/4.0) which permits unrestricted non-commercial use, distribution, and reproduction in any medium, provided the original work is properly cited. 


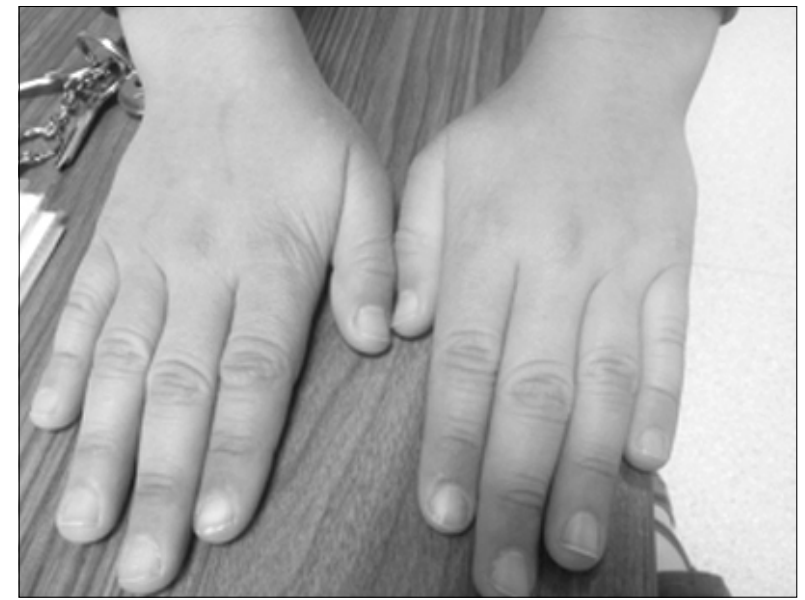

Fig. 1. Cyanosis in the patient's right and left fingers.

tory of RP.

The patient was diagnosed with conduct disorder according to the Diagnostic and Statistical Manual of Mental Disorders, 5th edition (DSM-V), and risperidone $1 \mathrm{mg} /$ day was initiated gradually for behavioral problems and impulse control. Two weeks after starting risperidone, the patient communicated with our clinic, he was describing cyanosis following pallor in his right and left fingers. During the clinical evaluation, we observed cyanosis in his right and left hands that was limited to the fingers (Fig. 1). His fingers were cold with palpation, we didn't observe necrosis, ulceration and the patient didn't describe pain. The patient was consulted to the general pediatrician and dermatologist for further evaluation. Neurological and rheumatological examinations were normal, and the dermatologist evaluated the patient's symptoms as RP. To examine RP etiology, common blood and urine count, routine biochemical tests, thyroid function tests, coagulation factors, sedimentation, CRP, rheumatoid factor, and antinuclear anticores were tested and all of them were normal. Risperidone dose was reduced to $0.5 \mathrm{mg} /$ day, but the patient's RP symptoms continued. So, we stopped risperidone therapy and suggested a periodic follow-up. One month after stopping risperidone, the patient didn't experience any pallor, or cyanosis in fingers and we started aripiprazole $5 \mathrm{mg} /$ day for behavioral problems. Six months later, the patient reported that he was free of RP symptoms.

In this case, we excluded other seconder causes of RP with anamnesis, physical examination, and laboratory tests. Risperidone therapy was the only potential cause for
RP. Therefore, we accepted the patient as a RP secondary to risperidone.

\section{DISCUSSION}

$\mathrm{RP}$ is defined as periodical vasospasms of peripheral vessels. It usually occurs with episodic and tri-phasic discoloration white, blue-purple, or red respectively. White discoloration represents ischemia, blue or purple discoloration shows deoxygenation, and red discoloration is a sign of reperfusion. Although our patient didn't describe any pain or paresthesia, in some cases, pain or paresthesia may accompany discoloration. ${ }^{5)}$

Prevalence of RP is known to be between 1-20\% and it is common in young females. Other risk factors can be sorted as; family history, migraine, cardiovascular diseases, estrogen treatment, smoking, alcohol, and low body mass index. However our case didn't represent these risk factors. On the contrary, our case was a medically healthy male, was not smoking or drinking alcohol, and had no family history of RP. ${ }^{12)}$

$\mathrm{RP}$ is classified as primary and secondary. Primary RP, in other terms Raynaud's Disease or idiopathic RP, is the term to define the absence of any etiological cause. Secondary RP is known as Raynaud's syndrome, and this term is used to define an underlying pathology that causes RP. ${ }^{5)}$ The most common cause of secondary RP is connective tissue diseases. In addition, trauma, hematological, neurological or arterial diseases, toxins, and drugs may also cause seconder RP. ${ }^{11)}$ Several psychotropic drugs inluding fluoxetine, citalopram, aripiprazole, atomoxetine, methylphenidate, and dextroamphetamine have

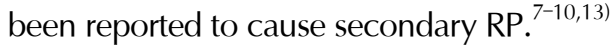

Although pathophysiology of RP isn't clearly understood, vasospasm of digital arterioles is thought to be a potential mechanism. Endothelial damage and following perivascular changes could be resulting with arteriolar spasm. Spasm of arterioles as a response to alpha-beta adrenergic and serotonergic receptors is the other potential mechanism. ${ }^{5)}$ Consistent with these mechanisms, there are case reports of RP due to serotonergic drugs. ${ }^{7,8)}$ Rudnick et al. ${ }^{7)}$ reported a 54-year-old woman who developed RP after increasing fluoxetine dose and the patient recovered five days after switching back to the previous dose. Another case of RP reported due to initiating citalopram in a 43-year-old women and the patient recov- 
ered a month after discontinuation. ${ }^{8)}$ On the other hand, there are several reports that selective serotonin reuptake inhibitors could be used in the treatment of RP. ${ }^{14,15)}$ Bolte and Avery ${ }^{15)}$ reported complete remission of RP in a 31-year-old nondepressed woman treated with fluoxetine. In addition, Skop and Brown ${ }^{16)}$ reported that peripheral serotonin causes vasodilation in a healthy vascular bed, and vasoconstriction in damaged endothelium. So, it can be considered that the peripheral vascular effects of serotonin are complex, and this discrepancy may be related to endothelial damage. In another case presentation, Camkurt et al. ${ }^{9)}$ reported a case of RP with aripiprazole which is an atypical antipsychotic with a partial agonism for $\mathrm{D}_{2}$ and $5 \mathrm{HT}_{1}$ a receptors, and an antagonism for $5 \mathrm{HT}_{2 \mathrm{a}}$. In this paper, it was suggested that RP could be associated with dopaminergic agonism or serotonergic effects of aripiprazole. In our case, risperidone, which has a $5 \mathrm{HT}_{2}$ receptor antagonism, might cause RP symptoms through the serotonin receptors.

Gökçen et al. ${ }^{13)}$ reported a dose-dependent RP developing from use of atomoxetine, which is a presynaptic norepinephrine transportation inhibitor. In this case report, it was suggested that atomoxetine might increase levels of norepinephrine in peripheral and central synapses, stimulate peripheral $\alpha_{1}$ and $\alpha_{2}$ receptors, and lead to prolonged vasoconstriction. In addition, Syed and Moore ${ }^{10)}$ reported four RP case due to methylphenidate and dextroamphetamine that have noradrenergic and dopaminergic effects. It is known that risperidone has a high affinity to $\alpha_{1}$-adrenergic receptors, and it may increase the plasma norepinephrine levels and sympathetic activity. ${ }^{4}$ In this context, these mechanisms could also be a potential cause of RP in our case. Furthermore, a study suggests that risperidone worsens vascular endothelial function in diabetic rats, which may be mediated by upregulation of VCAM-1, ICAM-1, and E-selectin. ${ }^{17)}$ Endothelial dysfunction and upregulation of the adhesion molecules might be another mechanism that induced RP in our case.

As far as we know, this is the first case of RP reported in the literature to occur because of risperidone use. We hope this paper will be a warning for clinicians who follow up the patients using risperidone. In addition, further investigations are needed to clarify the characteristics, risk factors, dose dependence, and potential mechanisms of risperidone-related RP.

\section{Acknowledgments}

This article was conducted at the Mersin University School of Medicine.

\section{REFERENCES}

1. Conley RR. Risperidone side effects. J Clin Psychiatry 2000;61 Supp/ 8:20-23; discussion 24-25.

2. Güneş S, Ekinci Ö, Direk MÇ, Yıldırım V, Okuyaz Ç, Toros F. Risperidone induced Pisa syndrome in a male adolescent. Clin Psychopharmacol Neurosci 2016;14:104-106.

3. Hosseini SH, Ahmadi A. Peripheral edema occurring during treatment with risperidone combined with citalopram. Case Rep Med 2012;2012:540732.

4. Leung JY, Barr AM, Procyshyn RM, Honer WG, Pang CC. Cardiovascular side-effects of antipsychotic drugs: the role of the autonomic nervous system. Pharmacol Ther 2012; 135:113-122.

5. O'connor CM. Raynaud's phenomenon. J Vasc Nurs 2001; 19:87-92.

6. Zenone T, Durieu I, Nagnoug F, Castell P, Levrat R. Raynaud phenomenon with organic microangiopathy and prolonged treatment with bromocriptine. Rev Med Interne 1996;17: 948-950.

7. Rudnick A, Modai I, Zelikovski A. Fluoxetine-induced Raynaud's phenomenon. Biol Psychiatry 1997;41:1218-1221.

8. Peiró AM, Margarit C, Torra M. Citalopram-induced Raynaud's phenomenon. Rheumatol Int 2007;27:599-601.

9. Camkurt MA, Gunes S, Tecimer E. Aripiprazole-induced Raynaud's phenomenon: An adolescent case. J Child AdolesC Psychopharmacol 2016;26:953-954.

10. Syed RH, Moore TL. Methy/phenidate and dextroamphetamineinduced peripheral vasculopathy. I Clin Rheumatol 2008; 14:30-33.

11. Ratchford EV, Evans NS. Raynaud's phenomenon. Vasc Med 2015;20:269-271.

12. Garner R, Kumari R, Lanyon P, Doherty M, Zhang W. Prevalence, risk factors and associations of primary Raynaud's phenomenon: systematic review and meta-analysis of observational studies. BMJ Open 2015;5:e006389.

13. Gökçen C, Kutuk MO, Coşkun Ş. Dose-dependent Raynaud's phenomenon developing from use of atomoxetine in a girl. J Child Adolesc Psychopharmacol 2013;23:428-430.

14. Coleiro B, Marshall SE, Denton CP, Howell K, Blann A, Welsh $\mathrm{KI}$, et al. Treatment of Raynaud's phenomenon with the selective serotonin reuptake inhibitor fluoxetine. Rheumatology (Oxford) 2001;40:1038-1043.

15. Bolte MA, Avery D. Case of fluoxetine-induced remission of Raynaud's phenomenon--a case report. Angiology 1993; 44:161-163.

16. Skop BP, Brown TM. Potential vascular and bleeding complications of treatment with selective serotonin reuptake inhibitors. Psychosomatics 1996;37:12-16. 
17. Aboul-Fotouh S, Elgayar N. Atypical antipsychotics such as risperidone, but not paliperidone, worsen vascular endothelial function via upregulation of adhesion molecules VCAM-1,
ICAM-1, and E-selectin in diabetic rats. Can J Physiol Pharmacol 2013;91:1119-1126. 